\title{
Impact of Elevated Systolic Arterial Pulmonary Pressure on Short and Long Term All-Cause Mortality After Acute Myocardial Infarction in the Elderly
}

\author{
Salim Barywani ( $\nabla$ salim.barywani@vgregion.se ) \\ University of Gothenburg \\ Magnus C Johansson \\ University of Gothenburg \\ Silvana kontogeorgos \\ University of Gothenburg \\ Zacharias Mandalenakis \\ University of Gothenburg \\ Per-Olof Hansson \\ University of Gothenburg
}

\section{Research Article}

Keywords: Systolic pulmonary artery pressure, Myocardial infarction, All-cause mortality, Post myocardial infarction heart failure

Posted Date: November 19th, 2021

DOI: https://doi.org/10.21203/rs.3.rs-1012546/v1

License: (c) (1) This work is licensed under a Creative Commons Attribution 4.0 International License.

Read Full License 


\section{Abstract}

Background: Reduced left ventricular ejection fraction (LVEF) is associated with increased mortality after myocardial infarction (MI). However, the prognostic impact of elevated systolic pulmonary artery pressure (SPAP) in the elderly patients with $\mathrm{Ml}$ is not well studied.

Purpose: We aimed to study the impact of elevated sPAP on one- and five-year all-cause mortality after acute $\mathrm{Ml}$ in patients 80 years of age and older.

Methods: Of a total number of 353 patients( $\geq 80$ years old)that were hospitalized with acute coronary syndrome, 162 patients presenting with acute $\mathrm{MI}$ and with available data of SPAP on echocardiography were included and followed-up for 5 years. The survival analyses were performed using Cox-Regression models adjusted for conventional risk factors including LVEF.

Results: Altogether 65 of 162 patients (40\%) had ST-segment elevation MI, and 121 (75\%) of patients were treated with percutaneous coronary intervention in the acute phase. Echocardiography during the admission revealed that 78 patients (48\%) had a LVEF $\leq 45 \%$ and 65 patients $(40 \%)$ had a SPAP $\geq 40$ $\mathrm{mmHg}$.

After one and five years of follow-up, $23 \%(n=33)$ and $53 \%(n=86)$ of patients died, respectively. A multivariable Cox-Regression analysis showed that the elevated SPAP was an independent predictor of increased mortality in both one and five years after acute $\mathrm{Ml}$; HR of 3.4(95\%, Cl 1.4-8.2, P 0.006) and HR of $2.0(95 \%, \mathrm{Cl} 1.2-3.4, \mathrm{P} 0.004)$ respectively, whereas LVEF did not show any statistically significant impact, neither on one- nor on five-year mortality (HR 1.4, 95\% Cl 0.8-2.4, $\mathrm{p}=0.158)$ and $(\mathrm{HR} 1.3,95 \% \mathrm{Cl}$ $0.6-2.9, p=0.469)$, respectively.

\section{Conclusion:}

Elevated SPAP is an independent risk factor for one- and five-year all-cause mortality in patients with acute $\mathrm{MI}$ and it seems to be a better prognostic factor for death than LVEF. The risk of all-cause mortality in MI patients increased with increasing SPAP.

\section{Introduction}

The risk factor with highest association to increased mortality and morbidity after acute myocardial infarction (MI) is post-MI heart failure (HF) in all age groups, specifically in the elderly patients ${ }^{1-9}$. Previous studies have identified several risk factors for impaired survival rate after $\mathrm{Ml}$, including reduced left ventricular ejection fraction (LVEF) as a marker for structural left ventricular systolic dysfunction ${ }^{10-}$ ${ }^{13}$.Mutlak et al preformed a prospective longitudinal observational study designed to determine predictors of post myocardial infarction $\mathrm{HF}$, and they demonstrated that $44 \%$ of the patients had systolic pulmonary artery pressure (SPAP) $>35 \mathrm{mmHg}$ after acute MI. In addition, elevated SPAP at the index admission was a useful marker in unmasking latent subclinical $\mathrm{HF}$ and predicting the development of overt $\mathrm{HF}^{14}$. 
SPAP is considered to be a hemodynamic marker of left ventricular dysfunction ${ }^{15}$.

.To the best of our knowledge, the prognostic impact of elevated systolic SPAP on mortality, specifically in the elderly is not studied. Therefore, we aimed to study the impact of elevated sPAP on short-and longterm all-cause death after acute $\mathrm{Ml}$ in elderly patients $\geq 80$ years.

\section{Methods}

\section{Study cohort}

Three hundred and fifty-three patients aged $\geq 80$ years hospitalized due to acute coronary syndrome at the two major Cardiology departments at Sahlgrenska University Hospital (SU), (SU/Sahlgrenska and SU/ Östra), affiliated with the University of Gothenburg during 2006-2007 were included consecutively. All patients presented with acute myocardial infarction and examined with echocardiography with adequate data on SPAP were included in the study and followed up regarding death for 5 years $(n=162)$. Treatment with percutaneous coronary intervention ( $\mathrm{PCl}$ ) or not was based on a pure clinical decision made by the cardiologist in charge. All PCls were performed at a joint $\mathrm{PCl}$ center for both hospitals. Patients were retrospectively identified from the hospital patient registry. Patients from other hospitals who were referred to SU only for $\mathrm{PCl}$ were excluded due to incomplete follow-up data. The study protocol was approved by the Ethical Committee at the University of Gothenburg.

\section{Echocardiography}

All echocardiography examinations were performed at the department of Clinical Physiology at Sahlgrenska University Hospital by trained echo technicians or physicians according to standardized protocol. Echocardiography data were retrieved from the echocardiographic reports. LVEF was measured using Simpson biplane or when not feasible by visual estimate. Left atrial area was measured in apical 4 chamber view. LV filling pressure was qualitatively estimated by pulsed wave Doppler of mitral and pulmonary vein flow as increased or normal ${ }^{16}$. Mitral regurgitation was analyzed by colour and continuous wave Doppler and considered present when there more than trace regurgitation. Aortic stenosis was considered present when the peak gradient was $\geq 25 \mathrm{mmHg}$. Reference values were based on an examined local healthy population from which regression equations had been constructed based on body surface area, weight and age. The equations were incorporated in a spreadsheet, resulting in a zscore and an increased parameter-value for an individual was defined as a $z$-score $\geq 2.0$. The reference limits where thus individually adjusted for each patient.

\section{Estimation of systolic pulmonary artery pressure}

Systolic pulmonary artery pressure (SPAP) was estimated by echocardiography from the tricuspid valve regurgitant jet velocity using the modified Bernoulli equation $4 v^{2}$ plus right atrial pressure ${ }^{17-18}$. Special care was taken to align the Doppler cursor with the tricuspid regurgitation jet. Right atrial (RA) pressure was estimated from characteristics of the inferior vena cava (IVC); based on the diameter and the 
respiratory variation in the diameter of the IVC: an IVC diameter $\leq 21 \mathrm{~mm}$ that collapses $>50 \%$ with a sniff suggested a a normal RA pressure of $5 \mathrm{mmHg}$, whereas an IVC diameter $\leq 21 \mathrm{~mm}$ that collapses $<50 \%$ or an IVC diameter $>21 \mathrm{~mm}$ that collapses $>50 \%$ with a sniff regarded as an intermediate value, $10 \mathrm{mmHg}$. AIVC diameter $>21 \mathrm{~mm}$ that collapses $<50 \%$ with a sniff or $<20 \%$ on quiet inspiration regarded as a high RA pressure of $15 \mathrm{mmHg}$.

\section{Statistics}

Categorical variable were described as percentages and compared using chi-square test or Fisher exact as appropriated. Continuous variables were described as means \pm standard deviation (SD) and compared using independent sample test or One-way analysis of covariance. To adjust for the underlying baseline characteristics and to analyze for probable association between different levels of the SPAP and mortality, the cohort was analyzed using multivariable Cox proportional-hazard regression models analyzing time to event. Kaplan-Meier analysis and univariable Cox proportional-hazard regression analysis were used to build multivariable models. In order to identify the lowest cut off level of the sPAP, over which increasing SPAP was associated with increased mortality multivariable models were built for a sPAP level as low as $30 \mathrm{mmHg}$ and upward with $5 \mathrm{mmHg}$ intervals. All collected parameters were included in the univariable models. Parameters with significant results $(p<.05)$ from the univariable models and without crossing Kaplan-Meier curves were included in the multivariable models.

Multivariable Cox regression models were built for the different levels of sPAP. The multivariable Cox models were assessed for proportional hazard assumption for covariates graphically with adjusted log minus log curves. The hazard ratios (HRs) with confidence intervals (Cls) and $p$-values were presented. All statistical analyses were performed using SPSS 22 statistical software.

$P$-value $<0.05$ was regarded as statistically significant.

\section{Laboratory analysis.}

All laboratory variables were analyzed, according to routine protocol, by the Clinical Chemistry Laboratory at Sahlgrenska University Hospital. Cockcroft-Gault formula was used to estimate the glomerular filtration rate (eGFR) in $\mathrm{ml} / \mathrm{min} / 1.73 \mathrm{~m}^{2}$.

\section{Clinical outcome data}

The primary endpoints were one-and five-year all-cause mortality after acute myocardial infarction. Data on time of death were obtained from the Swedish Cause of Death registry which includes all deaths of persons registered in Sweden.

\section{Results}

Clinical characteristics 
The clinical characteristics of the 66 patients with a sPAP $\geq 40 \mathrm{mmHg}$ and of the 96 patients with a sPAP $<40 \mathrm{mmHg}$ are shown in Table 1. 
Table 1

Demographic and clinical characteristics of the study patients, comparing patients with systolic arterial pulmonary pressure (SPAP) $\geqq 40 \mathrm{mmHg}$ and sPAP $<40 \mathrm{mmHg}$

\begin{tabular}{|c|c|c|c|}
\hline & $\mathrm{sPAP} \geqq 40 \mathrm{mmHg}(\mathrm{n}=66)$ & $\begin{array}{l}\text { sPAP }<40 \mathrm{mmHg} \\
(n=96)\end{array}$ & P-value \\
\hline Demographics & $84.4 \pm 2.8$ & $83.7 \pm 2.8$ & 0.089 \\
\hline \multicolumn{4}{|l|}{ Age, year } \\
\hline Gender, male & $32(48.5)$ & $58(60.4)$ & 0.133 \\
\hline Weight, kg & $70.7 \pm 15.4$ & $73.2 \pm 12.0$ & 0.265 \\
\hline Height, cm & $167.6 \pm 22.2$ & $169.5 \pm 8.8$ & 0.452 \\
\hline $\mathrm{BMI}, \mathrm{kg} / \mathrm{m}^{2}$ & $23.6 \pm 3.7$ & $25.4 \pm 3.8$ & 0.004 \\
\hline Smoking, yes & $6(9.5)$ & $5(5.3)$ & 0.321 \\
\hline Clinical Characteristics & $28(42.4)$ & $38(39.6)$ & 0.421 \\
\hline \multicolumn{4}{|l|}{ STEMI, yes } \\
\hline Non-STEMI, yes & $31(47.0)$ & $48(50.0)$ & 0.413 \\
\hline $\mathrm{PCl}$, yes & $44(66.7)$ & $77(80.2)$ & 0.051 \\
\hline Heart rate,bpm & $81.8 \pm 16.7$ & $80.8 \pm 29.7$ & 0.881 \\
\hline Systolic BP, mmHg & $145.6 \pm 28.6$ & $150.4 \pm 26.6$ & 0.296 \\
\hline Diastolic BP, mmHg & $85.8 \pm 16.1$ & $82.8 \pm 16.1$ & 0.271 \\
\hline Laboratory findings & $129.8 \pm 15.2$ & $131.7 \pm 17.0$ & 0.478 \\
\hline \multicolumn{4}{|l|}{ Hemoglobin, g/L } \\
\hline eGFR, $\mathrm{ml} / \mathrm{min} / 1.73 \mathrm{~m}^{2}$ & $49.1 \pm 19.7$ & $50.3 \pm 18.3$ & 0.682 \\
\hline Creatinine, umol/L & $110.0 \pm 104.2$ & $110.7 \pm 77.6$ & 0.961 \\
\hline Comobidities & 17(27.0) & 17(17.7) & 0.153 \\
\hline \multicolumn{4}{|l|}{ Atrial fibrillation, yes } \\
\hline History of heart failure, yes & $14(23.0)$ & 17(17.7) & 0.355 \\
\hline Hypertension, yes & $35(53.0)$ & $40(41.7)$ & 0.103 \\
\hline Diabetes, yes & $13(21.0)$ & 16(17.6) & 0.374 \\
\hline
\end{tabular}




\begin{tabular}{|c|c|c|c|}
\hline & $\mathrm{sPAP} \geqq 40 \mathrm{mmHg}(\mathrm{n}=66)$ & $\begin{array}{l}\text { sPAP }<40 \mathrm{mmHg} \\
(n=96)\end{array}$ & P-value \\
\hline Hyperlipidaemia, yes & $9(13.8)$ & $8(8.3)$ & 0.195 \\
\hline Previous stroke, yes & 11(19.6) & $10(11.0)$ & 0.284 \\
\hline Medications & $34(51.5)$ & $51(56.7)$ & 0.317 \\
\hline \multicolumn{4}{|l|}{$\beta$ - Blockers, yes } \\
\hline ACEl/ARB, yes & $20(30.3)$ & $26(27.1)$ & 0.517 \\
\hline diuretics, yes & $16(24.2)$ & 19(20.9) & 0.378 \\
\hline Calcium channel blocker, yes & $14(21.2)$ & $36(39.1)$ & 0.017 \\
\hline Statins, yes & 11(16.7) & $21(22.6)$ & 0.238 \\
\hline Digoxin, yes & $9(15.0)$ & $10(10.8)$ & 0.296 \\
\hline \multicolumn{4}{|c|}{$\begin{array}{l}\text { BMI, body mass index. STEMI, ST-elevation myocardial infarction. Non-STEMI, Non-ST-elevation } \\
\text { myocardial infarction. PCI, percutaneous coronary intervension. BP, blood pressure. eGFR, estimated } \\
\text { glomerular filtration rate. ACEI, angiotensin converting enzyme inhibitors. ARB, angiotensin receptor } \\
\text { blockers. }\end{array}$} \\
\hline
\end{tabular}

Patients with sPAP $\geq 40 \mathrm{mmHg}$ had lower BMI $(23.6 \pm 3.7$ vs. $25.4 \pm 3.8 \mathrm{~kg} / \mathrm{m} 2)$ and were less frequently treated with calcium channel blocker ( $21.2 \%$ vs. $39.1 \%$ ) compared to patients with a sPAP $<40 \mathrm{mmHg}$. There were no significant differences in gender, previous stroke or in number of patients treated with $\mathrm{PCl}$, betablockers, angiotensin converting enzyme inhibitors/angiotensin receptor blockers, diuretics, statins or digoxin.

\section{Echocardiographic findings}

The lowest cut-off level of sPAP over which increasing SPAP was associated with increased mortality rate was $40 \mathrm{mmHg}$. Patients with sPAP $\geq 40 \mathrm{mmHgmore}$ often had reduced LVEF (41.7\% vs. $49.5 \%$ ),elevated left ventricular filling pressure ( $43.9 \%$ vs. $21.6 \%)$, dilated left atrium $(54.2 \%$ vs. $33.0 \%)$, mitral valve regurgitation ( $56.9 \%$ vs. $25.0 \%)$, tricuspid valve regurgitation( $13.8 \%$ vs. $4.4 \%$ ) and aortic valve stenosis $(27.6 \%$ vs. $13.3 \%)$ compared to patients with sPAP $<40 \mathrm{mmHg}$, Table 2. 
Table 2

Echocardiographic characteristics of study patients, comparing patients with systolic arterial pulmonary pressure (sPAP) $\geq 40 \mathrm{mmHg}$ and $\mathrm{SPAP}<40 \mathrm{mmHg}$

\begin{tabular}{|c|c|c|c|}
\hline & $\mathrm{sPAP} \geqq 40 \mathrm{mmHg}(\mathrm{n}=66)$ & $\begin{array}{l}\text { sPAP }<40 \mathrm{mmHg} \\
(\mathrm{n}=96)\end{array}$ & P-value \\
\hline Left ventricular ejection fraction, \% & $41.7 \pm 10.6$ & $49.5 \pm 10.4$ & $<0.001$ \\
\hline Elevated left ventricular filling pressure, yes & $29(43.9)$ & $16(21.6)$ & $<0.001$ \\
\hline Dilated left ventricle, yes & $16(25.4)$ & $15(16.5)$ & 0.125 \\
\hline Dilated left atrium, yes & $32(54.2)$ & $29(30.2)$ & 0.008 \\
\hline Mitral valve regurgitation $\geq$ grad $1 / 4$, yes & $37(56.9)$ & $23(25.0)$ & $<0.001$ \\
\hline Tricuspid valve regurgitation $\geq$ grad $1 / 4$, yes & $9(13.8)$ & $4(4.4)$ & 0.036 \\
\hline Aortic valve stenosis, yes & $16(27.6)$ & $11(13.3)$ & 0.029 \\
\hline
\end{tabular}

\section{Outcome data}

After 5-years of follow-up 86 patients died (all-cause mortality: 53.0\%) while the 1-year all-cause mortality was $23.4 \%$ (38deaths). Patients with SPAP $\geq 40 \mathrm{mmHg}$ had a higher 5 -year mortality rate, of $69.6 \%$ (46 events) and 1-year mortality rate, of $34.8 \%$ ( 23 events), compared to patients with sPAP $<40 \mathrm{mmHg}, 41.6 \%$ (40 events) ( $p<0.001)$ for 5 -year mortality rate and 15.6\% (15 events) $(p=0.004)$ for 1-year mortality rate.

\section{Association between SPAP and 1-year mortality}

Table 3 illustrated the association between SPAP and 1-year all-cause mortality. 
Table 3

Univariate and multivariable Cox-regression analysis of factors for association with1-year all-cause mortality.

\begin{tabular}{|c|c|c|c|c|c|c|}
\hline \multirow[t]{2}{*}{ Variables } & \multicolumn{3}{|c|}{ Univariable } & \multicolumn{3}{|c|}{ Multivariable } \\
\hline & HR & $(95 \% \mathrm{Cl})$ & p & HR & $(95 \% \mathrm{Cl})$ & p \\
\hline Age, year & 1.03 & $\begin{array}{l}0.92- \\
1.15\end{array}$ & 0.602 & 0.97 & $\begin{array}{l}0.85- \\
1.11\end{array}$ & 0.639 \\
\hline Gender, male & 0.79 & $\begin{array}{l}0.42- \\
1.49\end{array}$ & 0.471 & 0.97 & $\begin{array}{l}0.31- \\
0.90\end{array}$ & 0.518 \\
\hline $\mathrm{sPAP} \geq 40 \mathrm{mmHg}$ & 2.46 & $\begin{array}{l}1.26- \\
4.62\end{array}$ & 0.008 & 2.63 & $\begin{array}{l}1.19- \\
5.84\end{array}$ & 0.017 \\
\hline$L V E F \leq 45 \%$ & 1.71 & $\begin{array}{l}0.88- \\
3.29\end{array}$ & 0.111 & 1.34 & $\begin{array}{l}0.61- \\
2.93\end{array}$ & 0.469 \\
\hline Diabetes Mellitus & 1.26 & $\begin{array}{l}0.57- \\
2.75\end{array}$ & 0.570 & 1.17 & $\begin{array}{l}0.49- \\
2.77\end{array}$ & 0.727 \\
\hline $\begin{array}{l}\text { Treatment with percutaneous coronary } \\
\text { intervention (PCl) }\end{array}$ & 0.56 & $\begin{array}{l}0.29- \\
1.09\end{array}$ & 0.086 & 0.72 & $\begin{array}{l}0.33- \\
1.6\end{array}$ & 0.424 \\
\hline Atrial fibrillation & 0.89 & $\begin{array}{l}0.39- \\
2.05\end{array}$ & 0.791 & 0.78 & $\begin{array}{l}0.31- \\
1.96\end{array}$ & 0.601 \\
\hline $\begin{array}{l}\text { Estimated glomerular filtration rate } \leq 35 \\
\mathrm{ml} / \mathrm{min}\end{array}$ & 1.94 & $\begin{array}{l}0.96- \\
3.95\end{array}$ & 0.067 & 1.99 & $\begin{array}{l}0.88- \\
4.48\end{array}$ & 0.097 \\
\hline
\end{tabular}

Multivariable analysis demonstrated an association between elevated SPAP and increased 1-year allcause mortality rate with a cutoff level at $>40 \mathrm{mmHg}(\mathrm{HR} 2.63,95 \% \mathrm{Cl} 1.19-5.84, \mathrm{p}=0.017)$, Figure 1 .

As a continuous variable, every increase of $5 \mathrm{mmHg}$ in SPAP was associated with $2.5 \%$ increased relative risk for all-cause mortality $(\mathrm{HR}=1.02,95 \%$ of $\mathrm{Cl} 1.00-1.05$ and $\mathrm{p}=0.05)$.

\section{Association between s PAP and 5-year mortality}

Table 4 illustrated the association between sPAP and 5-year mortality. 
Table 4

Univariate and multivariable cox-regression analysis of factors for association with 5-year all-cause mortality.

\begin{tabular}{|c|c|c|c|c|c|c|}
\hline \multirow[t]{2}{*}{ Variables } & \multicolumn{3}{|c|}{ Univariable } & \multicolumn{3}{|c|}{ Multivariable } \\
\hline & HR & $(95 \% \mathrm{Cl})$ & $\mathbf{p}$ & HR & $(95 \% \mathrm{Cl})$ & p \\
\hline Age, year & 1.09 & $\begin{array}{l}1.01- \\
1.17\end{array}$ & 0.021 & 1.02 & $\begin{array}{l}0.93- \\
1.11\end{array}$ & 0.693 \\
\hline Gender, male & 0.97 & $\begin{array}{l}0.64- \\
1.49\end{array}$ & 0.891 & 1.9 & $1.1-3.2$ & 0.019 \\
\hline $\mathrm{sPAP} \geq 40 \mathrm{mmHg}$ & 2.21 & $\begin{array}{l}1.44- \\
3.38\end{array}$ & $<0.001$ & 2.08 & $\begin{array}{l}1.25- \\
3.44\end{array}$ & 0.005 \\
\hline LVEF $\leq 45 \%$ & 1.26 & $\begin{array}{l}0.82- \\
1.92\end{array}$ & 0.293 & 1.42 & $\begin{array}{l}0.85- \\
2.438\end{array}$ & 0.158 \\
\hline Diabetes Mellitus & 1.92 & $\begin{array}{l}1.17- \\
3.14\end{array}$ & 0.010 & 1.73 & $\begin{array}{l}1.01- \\
2.96\end{array}$ & 0.048 \\
\hline $\begin{array}{l}\text { Treatment with percutaneous coronary } \\
\text { intervention (PCI) }\end{array}$ & 0.445 & $\begin{array}{l}0.29- \\
0.69\end{array}$ & $<0.001$ & 0.48 & $\begin{array}{l}0.29- \\
0.82\end{array}$ & 0.004 \\
\hline Atrial fibrillation & 2.32 & $\begin{array}{l}1.47- \\
43.67\end{array}$ & $<0.001$ & 2.04 & $\begin{array}{l}1.22- \\
3.40\end{array}$ & 0.006 \\
\hline $\begin{array}{l}\text { Estimated glomerular filtration rate } \leq 35 \\
\mathrm{ml} / \mathrm{min}\end{array}$ & 2.19 & $\begin{array}{l}1.36- \\
3.54\end{array}$ & 0.001 & 2.35 & $\begin{array}{l}1.37- \\
4.01\end{array}$ & 0.006 \\
\hline
\end{tabular}

Cox proportional-hazard regression multivariable models adjusted for important clinical variables and all significant variables from univariable models demonstrated an association between elevated sPAP and increased all-cause mortality rate with a cutoff level at $\geq 40 \mathrm{mmHg}(\mathrm{HR}=2.08,95 \% \mathrm{Cl} 1.25-3.44, \mathrm{p}=0.005$, Figure 2).

As a continuous variable, every increase of $5 \mathrm{mmHg}$ in SPAP was associated with $3 \%$ increased relative risk for all-cause mortality $(\mathrm{HR}=1.03,95 \%$ of $\mathrm{Cl}=1.01-1.04$ and $\mathrm{p}=0.003)$. Also male gender (HR 1.9, $95 \% \mathrm{Cl} 1.1-3.2, \mathrm{p}=0.019)$, atrial fibrillation (HR 2.04, 95\% $\mathrm{Cl} 1.22-3.40, \mathrm{p}=0.006)$ and eGFR $\leq 35$

$\mathrm{ml} / \mathrm{min} / 1.73 \mathrm{~m}^{2}$ (HR 2.35, 95\% Cl 1.37-4.01, $\mathrm{p}=0.006$ ) were associated with increased 5-year mortality rate. Treatment with percutaneous coronary intervention were associated with decreased 5-year mortality, (HR $0.48,95 \% \mathrm{Cl} 0.29-0.82, \mathrm{p}=0.004$ ).

\section{Discussions}


The results of the present study demonstrate an association between elevated SPAP levels and one as well as five-year mortality after acute $\mathrm{MI}$ in a cohort of elderly patients all 80 years of age or older at the baseline. After multivariable adjustment, sPAP with a cutoff level at $\geq 40 \mathrm{mmHg}$ was a strong independent predictor witha2-fold increase risk for both one- and five-year all-cause mortality. Every increase of $5 \mathrm{mmHg}$ in SPAP was associated with $2.5 \%$ and $3 \%$ increased relative risk for one- and fiveyear all-cause mortality, respectively.

Interestingly, sPAP was a stronger predictor for both short- and long-term mortality compared with LVEF which did not show any statistically significant impact in the Cox-regression multivariable models.

To our knowledge, the present study is the first to analyze the impact of sPAP on one- and five-year prognosis after acute $\mathrm{MI}$ in an elderly patient sample. A recent study has demonstrated an association between elevated SPAP and prognosis 6-months after $\mathrm{MI}^{19}$. However, in that study the patients were much younger compared with the patients in our study, with a mean age of years 64 years. However, the results of our study and the study published of Fan et al ${ }^{19}$ indicate the need for further randomized studies regarding the impact of SPAP on the prognosis after acute MI. Theoretically, as secondary preventive managements, treatment with renin-angiotensin-aldosterone system (RAAS) inhibitors might improve the prognosis.

The multivariable Cox proportional-hazards regression models found sPAP $\geq 40 \mathrm{mmHg}$ to be the only independent predictor for the one-year all-cause mortality after MI. Whereas, independent predictors of increased five-year all-cause mortality, beside the SPAP $\geq 40 \mathrm{mmHg}$, were also diabetes mellitus, treatment with $\mathrm{PCl}$, atrial fibrillation and eGFR $\leq 35 \mathrm{ml} / \mathrm{min}$. These results indicate that patients with elevated sPAP have a high risk for impaired survival already during the first year and these patients must be identified and tailored for secondary intervention managements as soon as possible. Interestingly, only $30 \%$ of patients with $\mathrm{SPAP} \geq 40 \mathrm{mmHg}$ were treated with angiotensin converting enzyme inhibitors or angiotensin receptor blockers, and only $51 \%$ with beta-blockers.

Pathophysiological mechanisms of elevated pulmonary artery pressure after acute $\mathrm{MI}$.

Acute myocardial infarction may results in decreased left ventricular (LV) function and thereby increasing LV filling pressures. The increased LV filling pressures transmits backwards into the lung circulation, leading to an increase in the pulmonary artery pressure (PAP). The elevated PAP is frequently associated with a reactive increase in pulmonary vascular resistance (PVR), resulting in a further increase in PAP20. Thus, the pulmonary circulation after MI is characterized by elevated PAP and PVR, which increases the afterload of the right ventricle (RV) and may contribute to RV dysfunction and eventually RV failure ${ }^{21}$.

The mechanism underlying the pulmonary vasoconstriction after $\mathrm{Ml}$ is not completely understood, but may involve alterations in angiotensin- $\mathrm{II}^{22}$ as well as endothelial dysfunction ${ }^{20}$.

The pulmonary vascular endothelium is the predominant site for the angiotensin-converting enzyme which hydrolyses angiotensin-I to angiotensin-II. The pulmonary circulation is very sensitive to the 
vasoconstrictive and proliferative effects of Angiotensin- $-\mathrm{I}^{23-24}$, hence, after MI develops progressive PHT and RVH with important pulmonary structural remodeling characterized by myofibroblasts proliferation and a vicious circle of cardiopulmonary dysfunction ${ }^{25}$.

One other reason for elevated PAP level could be ischemic mitral regurgitation, which is a common complication after $\mathrm{MI}$ and often associated with poor prognosis ${ }^{26-27}$.

The above mentioned evidence and mechanisms indicate that patients with elevated SPAP after acute MI might benefit from tailored and intensive treatment with angiotensin enzyme inhibitors and angiotensin receptor blockers, in order to prevent the development of post MI heart failure and thereby to improve survival.

\section{Strengths and limitations}

The data in the present study was collected from the medical records from any of the two largest cardiology centers in Gothenburg. All the echocardiography examinations were performed of echocardiography specialist at the department of clinical physiology. However, in this observational study, medical records were studied retrospectively. In addition, despite our efforts in collecting as much information as possible, some patient data were not available. Besides, despite adjustment, we cannot rule out residual confounding from unmeasured variables.

Furthermore, sPAP estimation by echocardiography includes an approximation of the right atrial pressure using inferior vena cava width and its respiratory variation. The gold standard would be right heart catheterization for measurement of pulmonary artery pressure, data which was not available in our present study.

\section{Clinical implication}

In clinical practice SPAP after acute MI can be used as a marker of poor prognosis and a target in secondary preventive managements in order to reduce the mortality and morbidity.

\section{Conclusions}

Elevated SPAP was an independent risk factor for one- and five-year all-cause mortality in patients with acute $\mathrm{MI}$ and seems to be a better prognostic factor for mortality than LVEF. We found that the risk of allcause mortality in patients with MI increased with increasing SPAP.

\section{List Of Abbreviations}

LVEF, left ventricular ejection fraction. LV, Left ventricle. RA, right atrium. SPAP, Systolic pulmonary artery pressure. MI, Myocardial infarction. STEMI, ST-elevation myocardial infarction. Non-STEMI, non-STelevation myocardial infarction. PCI, Percutaneous coronary intervension. HF, heart failure. IVC, inferior vena cava. eGFR, estimated glomerular filtration rate. BMI, body mass index. BP, blood pressure. ACEI, 
angiotensin converting enzyme inhibitors. ARB, angiotensin receptor blockers. HRs, hazard ratios. Cls, confidence intervals.

\section{Declarations}

Ethics approval and consent to participate: The Ethical Committee at the University of Gothenburg approved and granted permission to access and use the medical records described in the study. The ethical committee also ruled that no formal consent was necessary. The protocol was performed in accordance with the relevant guidelines and regulations according to the declaration of Helsinki.

Consent for publication: Not applicable.

Availability of data and material: The datasets used and/or analyzed during the current study are available from the corresponding author on reasonable request.

Competing interests. No conflict of interest is reported by the authors.

Funding: This work was supported by grants from the Västra Götalandsregionen, Sweden.

Authors' contributions: The corresponding author SB has built the database, performed the statistical analyses, generated tables and figures, interpreted results and was the major contributor in writing the manuscript. Also MJ, PH, ZM and SK have contributed in the interpreting of the results and writing the manuscript. All authors have read and approved the final manuscript.

\section{References}

1. Jernberg T, Hasvold P, Henriksson M, Hjelm H, Thuresson M, Janzon M. Cardiovascular risk in postmyocardial infarction patients: nationwide real-world data demonstrate the importance of a longterm perspective. Eur Heart J. 2015; 36(19):1163-70.

2. Steg PG, Dabbous OH, Feldman LJ, Cohen-Solal A, Aumont MC, López-Sendón J, et al. Global Registry of Acute Coronary Events Investigators. Determinants and prognostic impact of heart failure complicating acute coronary syndromes: observations from the Global Registry of Acute Coronary Events (GRACE). Circulation 2004; 109: pp. 494-499.

3. Sulo G, Igland J, Vollset SE, Nygård O, Ebbing M, Sulo E, et al. Heart failure complicating acute myocardial infarction; burden and timing of occurrence: a nation-wide analysis including 86771 patients from the Cardiovascular Disease in Norway (CVDNOR) Project. J Am Heart Assoc 2016; 5.

4. Bahit MC, Lopes RD, Clare RM, Newby LK, Pieper KS, Van de Werf F, et al. Heart failure complicating non-ST-segment elevation acute coronary syndrome: timing, predictors, and clinical outcomes. J Am Coll Cardiol HF 2013; 1: 223-229. 
5. Juillière Y, Cambou JP, Bataille V, Mulak G, Galinier M, Gibelin P, et al. FAST-MI Investigators. Heart failure in acute myocardial infarction: a comparison between patients with or without heart failure criteria from the FAST-MI registry. Rev Esp Cardiol 2012; 65:326-333.

6. Ng VG, Lansky AJ, Meller S, Witzenbichler B, Guagliumi G, Peruga JZ, et al. The prognostic importance of left ventricular function in patients with ST-segment elevation myocardial infarction: the HORIZONS-AMI trial. Eur Heart J Acute Cardiovasc Care 2014; 3: 67-77.

7. Sutton NR, Li S, Thomas L, Wang TY, de Lemos JA, Enriquez JR, et al. The association of left ventricular ejection fraction with clinical outcomes after myocardial infarction: findings from the Acute Coronary Treatment and Intervention Outcomes Network (ACTION) Registry-Get With the Guidelines (GWTG) Medicare-linked database. Am Heart J 2016; 178:65-73.

8. van der Bijl P, Abou R, Goedemans L, Gersh BJ, Holmes DR Jr, Ajmone Marsan N, et al. Left Ventricular Post-Infarct Remodeling: Implications for Systolic Function Improvement and Outcomes in the Modern Era. JACC Heart Fail. 2020; 8:131-140.

9. Ritsinger V, Nyström T, Saleh N, Lagerqvist B, Norhammar A. Heart failure is a common complication after acute myocardial infarction in patients with diabetes: A nationwide study in the SWEDEHEART registry. Eur J PrevCardiol. 2020 4:2047487319901063.

10. Multicenter Postinfarction Research G. Risk stratification and survival after myocardial infarction. $\mathrm{N}$ Engl J Med. 1983; 309:331-336.

11. White H.D, Norris R.M, Brown M.A, Brandt P.W, Whitlock R.M, Wild C.J. Left ventricular end-systolic volume as the major determinant of survival after recovery from myocardial infarction. Circulation. 1987; 76:44-51.

12. Halkin A, Stone GW, Dixon SR, Grines CL, Tcheng JE, Cox DA, et al. Impact and determinants of left ventricular function in patients undergoing primary percutaneous coronary intervention in acute myocardial infarction. Am J Cardiol. 2005; 96: 325-331

13. Solomon SD, Skali H, Anavekar NS, Bourgoun M, Barvik S, Ghali JK, et al. Changes in ventricular size and function in patients treated with valsartan, captopril, or both after myocardial infarction. Circulation. 2005; 11: 3411-3419.

14. DiabMutlak, Jonathan Lessick, ShemyCarasso, Michael Kapeliovich, Robert Dragu, Haim Hammerman, et al. Utility of pulmonary hypertension for the prediction of heart failure following acute myocardial infarction. Am J Cardiol. 2012.

15. Miller WL, Grill DE, Borlaug BA. Clinical features, hemodynamics, and outcomes of pulmonary hypertension due to chronic heart failure with reduced ejection fraction: pulmonary hypertension and heart failure. JACC Heart Fail. 2013;1(4):290-299.

16. Oh JK, Appleton CP, Hatle LK, Nishimura RA, Seward JB, Tajik AJ. The noninvasive assessment of left ventricular diastolic function with two-dimensional and Doppler echocardiography. J Am Soc Echocardiogr. 1997; 10:246-70.

17. Yildirimturk O, Tayyareci Y, Erdim R, Ozen E, Yurdakul S, Aytekin V, et al. Assesment of right atrial pressure using echocardiography and correlation withcatheterization. J Clin Ultrasound. 2011; 
39:337-343.

18. Kircher BJ, Himelman RB, Schiller NB. Noninvasive estimation of right atrial pressure from the inspiratory collapse of theinferior vena cava. Am J Cardiol. 1990; 66:493-496.

19. Fan, XT, Wang, SJ, Mujahid, H, Ji, XP. Effect of elevated pulmonary artery systolic pressure on shortterm prognosis in patients with acute myocardial infarction. Angiology. 2020; 71:567-72.

20. Moraes DL, Colucci WS \&Givertz MM (2000). Secondary pulmonary hypertension in chronic heart failure: the role of the endothelium in pathophysiology and management. Circulation; 102:17181723.

21. Guarracino F, Cariello C, Danella A, Doroni L, Lapolla F, Vullo C, et al. Right ventricular failure: physiology and assessment. Minerva Anestesiol; 71:307-312

22. Said SI. Mediators and modulators of pulmonary arterial hypertension. Am J Physiol Lung Cell Mol Physiol 291,547-558.

23. Lipworth B.J Dagg K.D. Vasoconstrictor effects of angiotensin II on the pulmonary vascular bed Chest. 1994; 105: 1360-1364

24. Morrell NW, Upton PD, Higham MA, Yacoub MH, Polak JM, Wharton J. Angiotensin II stimulates proliferation of human pulmonary artery smooth muscle cells via the AT1 receptor Chest. 1998: 114; 90S 91S.

25. Jean-François Jasmin, Angelino Calderone, Tack-Ki Leung, Louis Villeneuve, Jocelyn Dupuis. Lung structural remodeling and pulmonary hypertension after myocardial infarction: complete reversal with irbesartan. Cardiovascular Research. 2003: 58: 621-631.

26. Bursi F, Enriquez-Sarano M, Nkomo VT, Jacobsen SJ, Weston SA, Meverden RA, et al. Heart failure and death after myocardial infarction in the community: the emerging role of mitral regurgitation. Ciculation. 2005; 111: 295-301

27. Doron Aronson, NoaGoldsher, Robert Zukermann, Michael Kapeliovich, Jonathan Lessick, DiabMutlak, Salim Dabbah, et al. Ischemic mitral regurgitation and risk of heart failure after myocardial infarction. Arch Intern Med. 2006; 166: 2362-8.

\section{Figures}




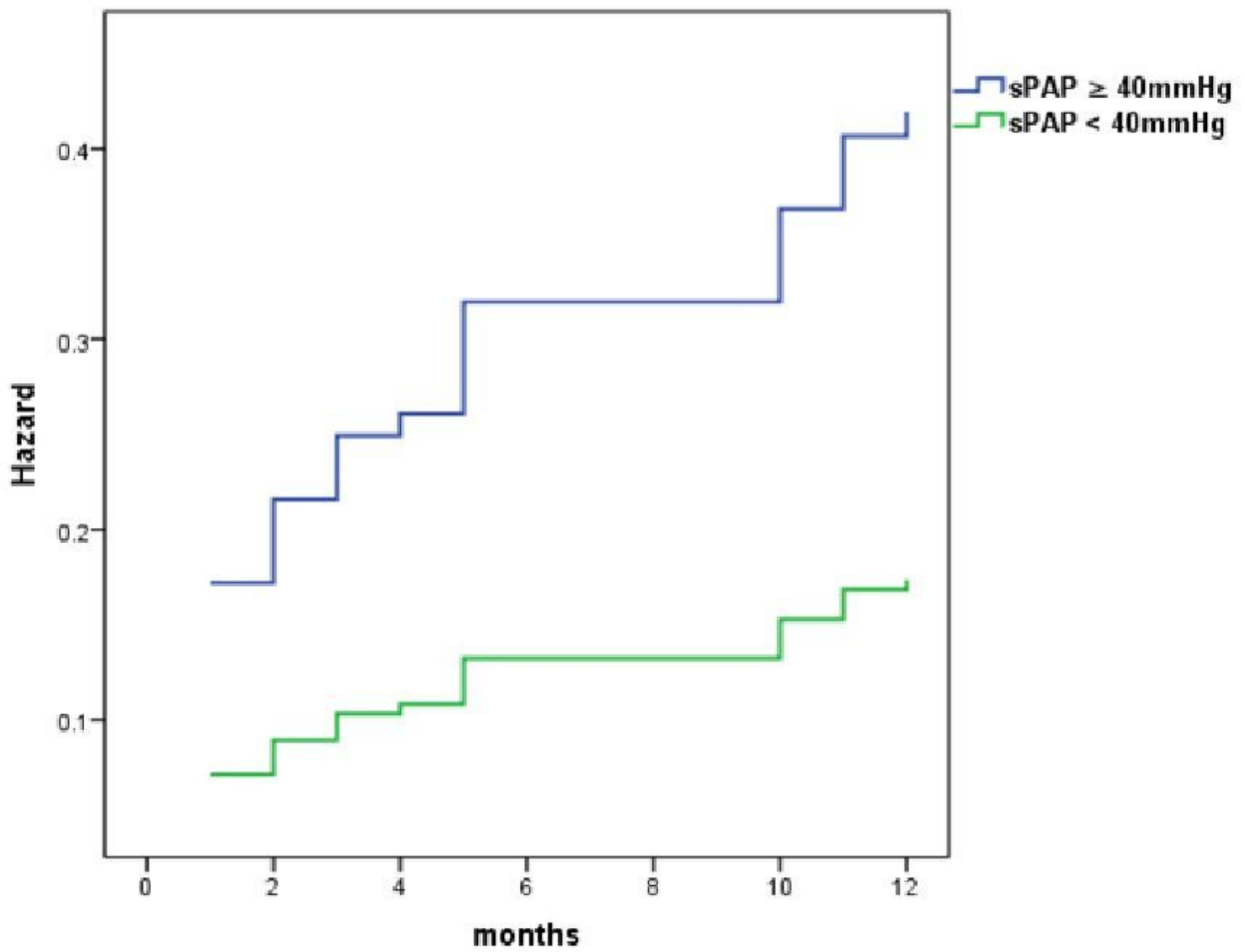

Figure 1

Comparison of 1-year risk of mortality between patients with sPAP $\geq 40$ and sPAP $<40 \mathrm{mmHg}$. 


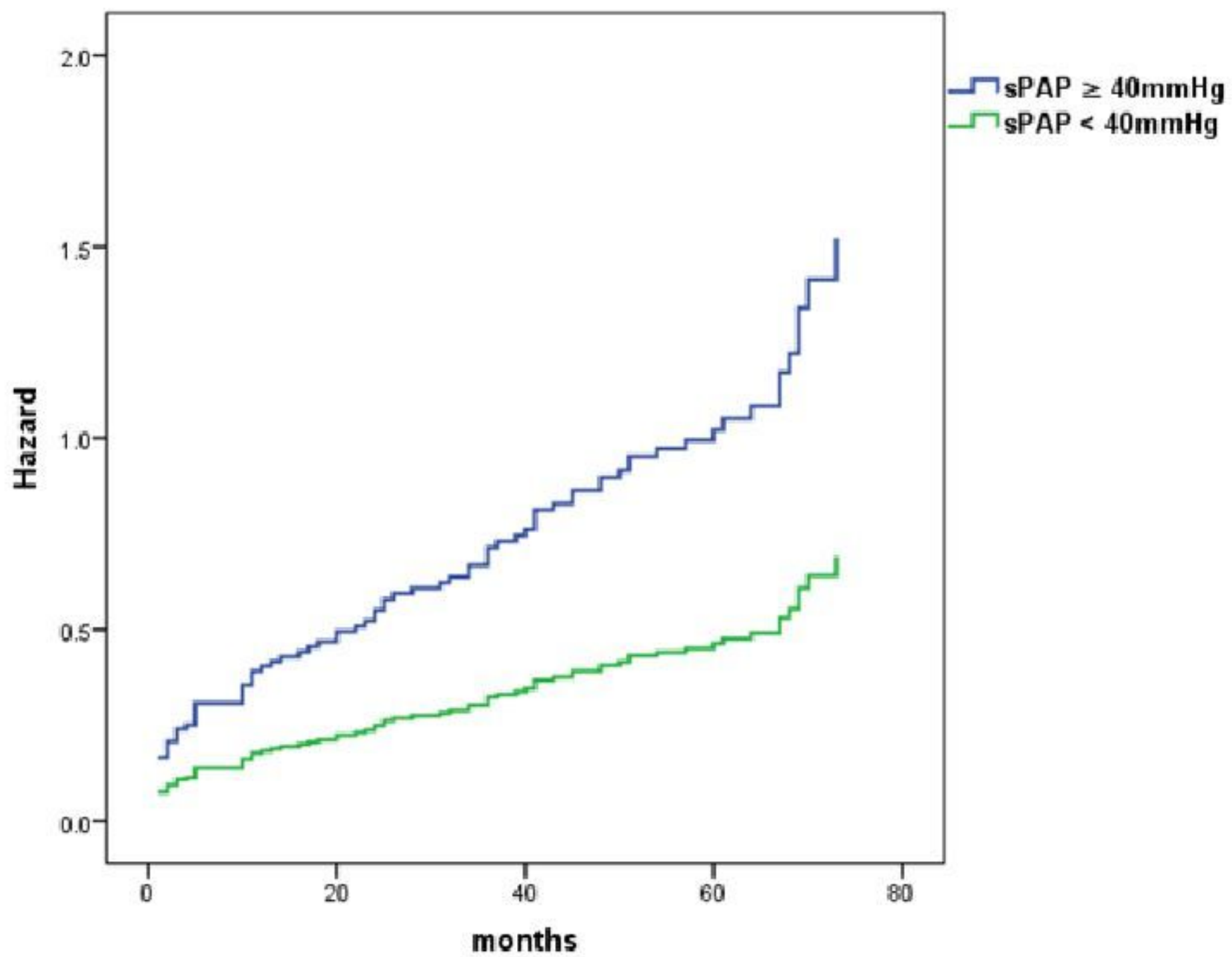

Figure 2

Comparison of 5-year risk of mortality between patients with $\mathrm{SPAP} \geq 40$ and $\mathrm{sPAP}<40 \mathrm{mmHg}$. 